\title{
Spirulina is an effective dietary source of zeaxanthin to humans
}

\author{
Bolan $\mathrm{Yu}^{1,2}$, Jie Wang ${ }^{3}$, Paolo M. Suter ${ }^{4}$, Robert M. Russell ${ }^{2}$, Michael A. Grusak ${ }^{5}$, Yin Wang ${ }^{6}$, \\ Zhixu Wang ${ }^{7}$, Shian Yin $^{3}$ and Guangwen Tang ${ }^{2 *}$ \\ ${ }^{1}$ Third Affiliated Hospital of Guangzhou Medical University, Guangzhou, People's Republic of China \\ ${ }^{2}$ Jean Mayer US Department of Agriculture Human Nutrition Research Center on Aging at Tufts University, 711 Washington \\ Street, Boston, MA, USA \\ ${ }^{3}$ National Institute for Nutrition and Food Safety, Beijing, People's Republic of China \\ ${ }^{4}$ University Hospital, Zurich and Nestlé Foundation, Lausanne, Switzerland \\ ${ }^{5}$ US Department of Agriculture/Agricultural Research Service, Children's Nutrition Research Center, Baylor College of \\ Medicine, Houston, TX, USA \\ ${ }^{6}$ Zhejiang Academy of Medical Sciences, Hangzhou, People's Republic of China \\ ${ }^{7}$ Nanjing Medical University, Nanjing, People's Republic of China \\ (Submitted 4 May 2011 - Final revision received 14 August 2011 - Accepted 3 October 2011 - First published online 7 February 2012)
}

\begin{abstract}
Zeaxanthin is a predominant xanthophyll in human eyes and may reduce the risk of cataracts and age-related macular degeneration. Spirulina is an algal food that contains a high concentration of zeaxanthin. In order to determine the zeaxanthin bioavailability of spirulina for dietary supplementation in humans, spirulina was grown in nutrient solution with ${ }^{2} \mathrm{H}_{2} \mathrm{O}$ for carotenoid labelling. Single servings of ${ }^{2} \mathrm{H}$-labelled spirulina (4.0-5.0 g) containing $2 \cdot 6-3.7 \mathrm{mg}$ zeaxanthin were consumed by fourteen healthy male volunteers (four Americans and ten Chinese) with $12 \mathrm{~g}$ dietary fat. Blood samples were collected over a $45 \mathrm{~d}$ period. The serum concentrations of total zeaxanthin were measured using HPLC, and the enrichment of labelled zeaxanthin was determined using LC-atmospheric pressure chemical ionisation-MS (LC-APCI-MS). The results showed that intrinsically labelled spirulina zeaxanthin in the circulation was detected at levels as low as $10 \%$ of the total zeaxanthin for up to $45 \mathrm{~d}$ after intake of the algae. A single dose of spirulina can increase mean serum zeaxanthin concentration in humans from 0.06 to $0.15 \mu \mathrm{mol} / \mathrm{l}$, as shown in our study involving American and Chinese volunteers. The average $15 \mathrm{~d}$ area under the serum zeaxanthin response curve to the single dose of spirulina was $293 \mathrm{nmol} \times \mathrm{d} / \mu \mathrm{mol}$ (range 254-335) in American subjects, and $197 \mathrm{nmol} \times \mathrm{d} / \mu \mathrm{mol}$ (range 154-285) in Chinese subjects. It is concluded that the relative bioavailability of spirulina zeaxanthin can be studied with high sensitivity and specificity using ${ }^{2} \mathrm{H}$ labelling and LC-APCI-MS methodology. Spirulina can serve as a rich source of dietary zeaxanthin in humans.
\end{abstract}

\section{Key words: Zeaxanthin: Spirulina: Bioavailability: ${ }^{2} \mathbf{H}$ labelling}

Zeaxanthin and its structural isomer lutein are the most prevalent xanthophylls found in the human body. They are highly concentrated in the retina of human eyes. Zeaxanthin is the major component in the central macula, while lutein is predominant in the peripheral area ${ }^{(1,2)}$. It is believed that zeaxanthin and lutein function as blue-light filters and reactive oxygen species scavengers in the retina to protect the cells from oxidative damage $e^{(3,4)}$

Numerous studies have suggested that zeaxanthin and lutein are crucial for visual health. In animal models (in monkeys), zeaxanthin and lutein have been found to be important for the development and maintenance of normal distribution of the retinal pigment epithelium ${ }^{(5,6)}$; retinal zeaxanthin has also been shown to protect the photoreceptors from light-induced damage in quail eyes ${ }^{(7,8)}$. In human subjects, some epidemiological and clinical researchers have demonstrated that high levels of zeaxanthin and lutein intake are associated with significantly decreased risks of cataract and age-related macular degeneration ${ }^{(9-11)}$.

Because humans cannot synthesise xanthophylls, dietary intake of xanthophyll-containing foods is critical to provide these phytonutrients to our bodies. In the US population, the average intake of lutein and zeaxanthin together is about $2 \mathrm{mg} / \mathrm{d}^{(12)}$, which is three times less than the dose of lutein and zeaxanthin that has been linked with a decreased risk of age-related macular degeneration and cataracts

Abbreviations: AUC, area under the curve; MeOH, methanol; MTBE, methyl tert-butyl diethyl ether; LC-APCI-MS, LC-atmospheric pressure chemical ionisation-MS.

*Corresponding author: Dr G. Tang, fax +1 6175563344 , email guangwen.tang@tufts.edu 
$(6 \mathrm{mg} / \mathrm{d})^{(11)}$. Therefore, lutein and zeaxanthin supplements have been suggested for visual health in people with low dietary intake, especially for older adults.

However, although lutein is abundant in many green leafy vegetables such as kale and spinach, only a few kinds of food contain high concentrations of zeaxanthin ${ }^{(13,14)}$. In cooked egg-yolk, maize and orange pepper, zeaxanthin concentrations are about 587, 202 and $1665 \mu \mathrm{g} / 100 \mathrm{~g}$ fresh weight, respectively ${ }^{(13)}$. Spirulina is an alga that is rich in carotenoids, including zeaxanthin ${ }^{(15-18)}$. In the strain of spirulina studied in the present investigation, the concentration of zeaxanthin as a dried powder can reach $74000 \mu \mathrm{g} /$ $100 \mathrm{~g}^{(19)}$. Previous studies in animal models as well as in human subjects have demonstrated that $\beta$-carotene from spirulina has a high bioavailability and a high bioconversion to vitamin A factor ${ }^{(19)}$; however, no studies on spirulina zeaxanthin have been reported.

In the present report, the enrichment of spirulina zeaxanthin in serum and its bioavailability in humans have been determined. A single serving of intrinsically ${ }^{2} \mathrm{H}$-labelled spirulina was consumed by American and Chinese healthy males. Their plasma samples were collected up to $45 \mathrm{~d}$ post- spirulina supplementation. The concentration and isotopic enrichment of spirulina zeaxanthin were analysed using $\mathrm{C}_{30}$ columnbased HPLC and LC-atmospheric pressure chemical ionisation-MS (LC-APCI-MS). The results were used to calculate a relative bioavailability (the change in plasma concentration in response to a test meal) ${ }^{(20)}$, which demonstrated that spirulina is a rich source of dietary zeaxanthin in both American and Chinese volunteers.

\section{Materials and methods}

\section{Subjects and study design}

The present study was conducted according to the guidelines laid down in the Declaration of Helsinki and all procedures involving human subjects were approved by the Institutional Review Board of Tufts Medical Center and the Institute of Nutrition and Food Hygiene Ethical Review Committee of the Chinese Academy of Preventative Medicine. Informed consent was obtained from all subjects under the guidelines established.

The human studies were conducted in China and the USA in 2006 and 2008, respectively. For this study, four American males (two African Americans and two Caucasians) and ten Chinese males were recruited separately. The volunteers were healthy, non-smoking adults and were not taking vitamin supplements at the time of the study. All subjects were instructed to eat a low-carotenoid diet for 2 weeks before taking the study dose. On day 1, each subject was given a spirulina supplement of $4 \mathrm{~g}$ (for American volunteers) or $5 \mathrm{~g}$ (for Chinese volunteers) with a carotene-free liquid formulated breakfast. The ingredients of this liquid breakfast contained banana, coconut milk, whey protein, glucose polymer, white sugar and water, which provided $12 \mathrm{~g}$ fat $(26 \%$ of total energy), $4 \mathrm{~g}$ protein ( $4 \%$ of total energy) and $74 \mathrm{~g}$ carbohydrate (70\% of total energy), with a total energy content of $1668 \mathrm{~kJ}$ (399 kcal).

Fasting blood samples $(10 \mathrm{ml})$ were collected from all subjects before supplementation as the baseline. Blood samples $(10 \mathrm{ml})$ were collected from all subjects at 0 (fasting blood, just before breakfast), and 6, 8, 11 and $13 \mathrm{~h}$ after intake of the supplement on day 1 . Blood was drawn at 0,5 and $11 \mathrm{~h}$ on day 2 , and at 0 and $11 \mathrm{~h}$ on day 3 . Fasting blood samples $(10 \mathrm{ml})$ were obtained on days $4,5,6,7,11,13,15,19,23$, 27, 32, 39 and 45. Due to the schedules of the volunteers, time points varied slightly $( \pm 1 \mathrm{~d})$ for some subjects and two subjects had a shorter period of intervention (a minimum of $23 \mathrm{~d}$ ).

\section{Chemicals and materials}

Most of the solvents used in this study including chloroform, methanol $(\mathrm{MeOH})$, hexane, ethanol, tert-butyl methyl diethyl ether (MTBE), tetrahydrofurane were HPLC-grade and purchased from Sigma (St Louis, MO, USA). Diethyl ether was from Fisher Scientific (Fair Lawn, NJ, USA). $\mathrm{NH}_{2}$ cartridge columns were from Phenomenex (Torrance, CA, USA).

\section{Preparation of ${ }^{2} \mathrm{H}$ labelled spirulina}

${ }^{2} \mathrm{H}$ labelled spirulina (Spirulina platensis) was grown in liquid culture at the US Department of Agriculture Agricultural Research Service, Children's Nutrition Research Center in Houston, TX, USA as previously described ${ }^{(19)}$. Briefly, a liquid stock culture of spirulina cells was obtained from the University of Texas Culture Collection of Algae (UTEX no. LB2340; University of Texas, Austin, TX, USA), inoculated into 20-litre glass carboys, and grown in a sterilised artificial seawater medium enriched with 23 atom $\%{ }^{2} \mathrm{H}_{2} \mathrm{O}$. After $10-12 \mathrm{~d}$ of growth, the spirulina cultures were harvested, freeze-dried and shipped to the Carotenoids and Health Laboratory of the US Department of Agriculture Human Nutrition Research Center on Aging at Tufts University (Boston, MA, USA), where the freeze-dried spirulina was powdered, packed into capsules and stored at $-80^{\circ} \mathrm{C}$ immediately. Spirulina capsules for the China study were shipped by air, on dry ice, to the National Institute for Nutrition and Food Safety, Beijing, China. All spirulina capsules were stored at $-80^{\circ} \mathrm{C}$ until being analysed or consumed by the study subjects.

\section{Sample preparation}

Whole blood samples were protected from light using aluminium foil, incubated at $37^{\circ} \mathrm{C}$ for $30 \mathrm{~min}$, and centrifuged at $4^{\circ} \mathrm{C}, 800 \mathrm{~g}$ for $15 \mathrm{~min}$ to separate the serum. Serum samples collected from Chinese subjects were stored at $-20^{\circ} \mathrm{C}$ first (less than 2 months) and then shipped by air, on dry ice, to the Carotenoids and Health Laboratory of HNRCA in Boston, MA, USA, where the samples were stored at $-80^{\circ} \mathrm{C}$ until analysis. Due to the light sensitivity of carotenoids, the extractions and analyses of carotenoids were performed under red light. 
To extract carotenoids from spirulina, $1.0 \mathrm{mg}$ of dried spirulina powder was mixed with $10 \mathrm{ml} \mathrm{MeOH}$ for $1 \mathrm{~h}$ in a shaking incubator at $120 \mathrm{rpm}$. The mixture was centrifuged at $3000 \mathrm{rpm}$ for $5 \mathrm{~min}$, and the $\mathrm{MeOH}$ extract was transferred into a $50 \mathrm{ml}$ volumetric flask. The residue was further extracted with $10 \mathrm{ml}$ of tetrahydrofurane, vortexed and centrifuged at $3000 \mathrm{rpm}$ for $5 \mathrm{~min}$. Extraction of tetrahydrofurane was repeated three or four times, and all tetrahydrofurane extracts were combined with the $\mathrm{MeOH}$ extract in the same flask. The final volume of the spirulina extract was adjusted to exactly $50 \mathrm{ml}$ in the volumetric flask, and $1 \mathrm{ml}$ of the extract was transferred to a $10 \mathrm{ml}$ glass tube, dried under $\mathrm{N}_{2}$ and resuspended with $1 \mathrm{ml}$ of ethanol for HPLC and LC-APCI-MS analyses.

To extract carotenoids from human serum, $500 \mu \mathrm{l}$ serum samples, $500 \mu \mathrm{l}$ of $0.85 \%$ saline, $60 \mu \mathrm{l}$ internal standard (echinenone in ethanol with absorbance of $0 \cdot 1-0.2$ measured at $460 \mathrm{~nm})$, and $5 \mathrm{ml} \mathrm{CHCl}_{3}-\mathrm{MeOH}(2: 1, \mathrm{v} / \mathrm{v})$ were added into $15 \mathrm{ml}$ disposable glass tubes. The mixture was vortexed, centrifuged at $3000 \mathrm{rpm}$ for $5 \mathrm{~min}$, and the lower layer was removed to another $15 \mathrm{ml}$ tube. After removal of the chloroform layer, $3 \mathrm{ml}$ hexane and $1 \mathrm{ml}$ ethanol were added to the remaining aqueous phase, vortexed and centrifuged again. The upper layer was combined with the $\mathrm{CHCl}_{3}-\mathrm{MeOH}$ extract. All samples were extracted in duplicates, and their chloroform and hexane layers were combined together, dried under $\mathrm{N}_{2}$ and finally resuspended in $120 \mu \mathrm{l}$ ethanol to make ready for HPLC analysis.

For LC-APCI-MS analysis, serum was extracted as done previously, but the final dried residue was resuspended with $100 \mu \mathrm{l}$ of $\mathrm{CHCl}_{3}$. The $\mathrm{CHCl}_{3}$ solution was added to the centre of an aminopropyl column $(500 \mathrm{mg} / 3 \mathrm{ml})$ in the Vac Elut apparatus, which was conditioned with $2 \mathrm{ml}$ of hexane. An additional $100 \mu \mathrm{l}$ of $\mathrm{CHCl}_{3}$ was used to wash the glass tube, and also transferred to the column. Under a gentle vacuum, the column containing the serum extracts was washed with $3 \mathrm{ml}$ of hexane once, and eluted with $3 \mathrm{ml}$ of diethyl ether with $3 \%$ acetic acid. The elution was collected in a $5 \mathrm{ml}$ glass tube, dried under $\mathrm{N}_{2}$ and resuspended with $120 \mu$ l of ethanol to make ready for LCAPCI-MS analysis.

\section{HPLC analysis}

The concentrations of xanthophylls in spirulina and human serum were analysed using a Waters HPLC coupled with a Waters 994 Programmable Photodiode Array Detector (Waters Corporation, Milford, MA, USA) and a semi-micro bore $\mathrm{C}_{30}$ column $(3 \mu \mathrm{m}, 150 \mathrm{~mm} \times 3.0 \mathrm{~mm}$; YMC, Wilmington, NC, USA). The HPLC mobile phase A contained MeOH, MTBE and $1.5 \%$ ammonium acetate in water (85:12:3, by vol.); and phase B contained methanol, MTBE and 1.0\% ammonium acetate in water (8:90:2, by vol.). The gradient procedure, at a flow rate of $0.4 \mathrm{ml} / \mathrm{min}$, was as follows: $0 \% \mathrm{~B}$ isocratic (0-3 min), $0 \% \mathrm{~B}-20 \% \mathrm{~B}$ linear gradient (3-10 min), $20 \%$ $\mathrm{B}-55 \% \mathrm{~B}$ linear gradient $(10-18 \mathrm{~min}), 55 \% \mathrm{~B}-95 \% \mathrm{~B}$ linear gradient $(18-33 \mathrm{~min}), 95 \% \mathrm{~B}-0 \% \mathrm{~B}$ linear gradient $(33-37 \mathrm{~min}), 0 \% \mathrm{~B}$ isocratic $(37-40 \mathrm{~min})$. The total run time was $40 \mathrm{~min}$ and the injection volume was $20 \mu \mathrm{l}$. The UV-Vis spectra of all carotenoids were recorded in the range of 250-600 nm, and peak identification was based on comparisons with the retention times and absorption spectra of known carotenoid standards in our laboratory. Data acquisition and processing were performed using Empower Pro software (version 2.0; Waters Corporation).

\section{LC-atmospheric pressure chemical ionisation-MS analysis}

Analysis of zeaxanthin enrichment was performed with an Agilent LC-MS (Agilent Technologies, Santa Clara, CA, USA) equipped with an Agilent HPLC, autosampler, UV detector, HP1100MSD with APCI interface and a $C_{30}$ column $(3 \mu \mathrm{m}$, $150 \mathrm{~mm} \times 4.6 \mathrm{~mm}$, Bischoff Chromatography, Leonberg, Germany). The HPLC mobile phase A contained $\mathrm{MeOH}$, MTBE and $1.5 \%$ ammonium acetate in water $(83: 15: 2$, by vol.); and phase B contained $\mathrm{MeOH}, \mathrm{MTBE}$ and 1.0\% ammonium acetate in water (8:90:2, by vol.). Gradient procedures (flow rate $1 \mathrm{ml} / \mathrm{min}$ ) were changed as follows: $0 \% \mathrm{~B}$ isocratic $(0-2 \mathrm{~min}), 0 \% \mathrm{~B}-5 \% \mathrm{~B}$ linear gradient (2-10 min), $5 \% \mathrm{~B}-55 \% \mathrm{~B}$ linear gradient (10-18 min), $55 \% \mathrm{~B}-95 \% \mathrm{~B}$ linear gradient $(18-20 \mathrm{~min}), 95 \% \mathrm{~B}-0 \% \mathrm{~B}$ linear gradient $(20-21 \mathrm{~min}), 0 \% \mathrm{~B}$ isocratic $(21-40 \mathrm{~min})$. The total run time was $40 \mathrm{~min}$ and the injection volume was $60 \mu \mathrm{l}$. The UV-Vis spectra of peaks were recorded in the range of $250-600 \mathrm{~nm}$ and the mass spectra were recorded using the following parameters: polarity, positive; mass range, $\mathrm{m} / \mathrm{z}$ 550-590; fragmentor, 90; gain, 20.00; threshold, 150; and stepsize, 0·1. Data acquisition and process were performed using ChemStations software (Agilent Technologies).

\section{Data process and statistical analysis}

The enrichment of labelled zeaxanthin was calculated by integrating the areas of labelled and unlabelled zeaxanthin in extracted ion chromatographs and by using the following equations $(1-3)$ :

$$
\begin{gathered}
\sum \text { Unlabelled zeaxanthin }=\sum \text { areas of } m / z 569-571 . \\
\sum \text { Labelled zeaxanthin }=\sum \text { areas of } m / z 573-583 .
\end{gathered}
$$

Enrichment of labelled zeaxanthin from spirulina (\%)

$$
\begin{aligned}
= & \left(\sum \text { labelled zeaxanthin } \times 100\right) /\left(\sum\right. \text { labelled zeaxanthin } \\
& \left.+\sum \text { unlabelled zeaxanthin }\right) .
\end{aligned}
$$

The serum response of labelled zeaxanthin was calculated using equation 4 , in which 0.0435 is the serum volume in litres/kg of body weight:

$$
\begin{aligned}
& \text { Serum response of labelled zeaxanthin }(\mathrm{nmol}) \\
& =\text { enrichment of labelled zeaxanthin in total zeaxanthin } \\
& \quad \times \text { total serum zeaxanthin concentration } \\
& \quad \times \text { body weight }(\text { in } \mathrm{kg}) \times 0.0435 \text {. }
\end{aligned}
$$




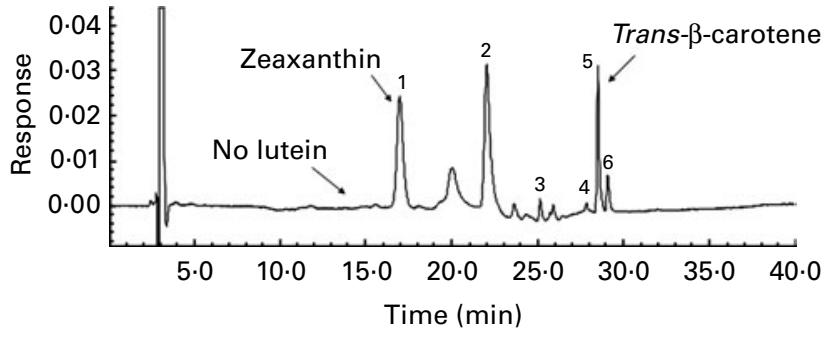

Fig. 1. Separation of carotenoids from ${ }^{2} \mathrm{H}$-labelled spirulina in this study by HPLC analysis. Peaks were identified as: (1) trans-zeaxanthin; (2) chlorophyll; (3) cryptoxanthin; (4) 13-cis- $\beta$-carotene; (5) all-trans- $\beta$-carotene; (6) 9-cis- $\beta$-carotene.

The area under the curve (AUC) of labelled zeaxanthin was calculated by using the curve of serum response of labelled zeaxanthin (nmol, as $y$ axis) $v$. time (day, as $x$ axis) via Integral-curve of Kaleidagraph software (version 3.5; Synergy Software, Reading, PA, USA). For all subjects, the AUC up to $15 \mathrm{~d}\left(\mathrm{AUC}_{0-15 \mathrm{~d}}\right.$ ) was calculated directly or calculated proportionally between the two nearest time points.

The average response to labelled spirulina zeaxanthin in the circulation was calculated using equation 5 :

Average serum response to labelled spirulina zeaxanthin

$(\mathrm{nmol} \times \mathrm{d} / \mu \mathrm{mol})=\mathrm{AUC}_{0-15} \mathrm{~d}$ of labelled

spirulina zeaxanthin/consumed zeaxanthin dose ( $\mu \mathrm{mol})$.

All statistical analyses were performed using Graphpad Prism for Windows software (version 4.0; GraphPad Software, San Diego, CA, USA). An unpaired $t$ test was used to assess the significance of differences of age, body weight, BMI values, baseline concentrations of xanthophylls and serum responses to labelled spirulina zeaxanthin between American and Chinese subjects.

\section{Results}

\section{Characteristics of American and Chinese subjects}

As previously mentioned, two groups of middle-aged, healthy, non-smoking males were recruited in the USA $(n 4)$ and China ( $n$ 10), respectively. The age range of American subjects is
46-52 (49.3 (SD 2.8)) years; weight range is $68.9-83.5(76 \cdot 3$ (SD $6 \cdot 1) \mathrm{kg}$ ); and BMI range is $23 \cdot 1-26.5(25 \cdot 5(\mathrm{SD} 1.6)) \mathrm{kg} / \mathrm{m}^{2}$. The age range of Chinese subjects is $41-57$ ( $48 \cdot 1$ (SD 5.7)) years; weight range is $52.2-78.4(66.7$ (SD 8.1$)) \mathrm{kg}$; and BMI range is $17.9-27.4(23.4(\mathrm{sD} 3 \cdot 1)) \mathrm{kg} / \mathrm{m}^{2}$. Although the mean values of age, body weight and BMI of American subjects were higher than those of Chinese subjects, there were no statistically significant differences between them for these characteristics.

The carotenoid concentrations of all subjects in the two groups were in the reported ranges ${ }^{(21)}$ (data not shown). The range of lutein concentrations was $0 \cdot 12-0 \cdot 18 \mu \mathrm{mol} / 1$ in the American group and $0.27-0.52 \mu \mathrm{mol} / 1$ in the Chinese group, while the range of zeaxanthin concentrations was 0.04-0.07 and 0.05-0.09 $\mu \mathrm{mol} / 1$ in the American and Chinese groups, respectively.

\section{Quantification of ${ }^{2} \mathrm{H}$-labelled zeaxanthin in spirulina}

HPLC analyses showed that in the spirulina produced for this study, trans-zeaxanthin and trans- $\beta$-carotene were the two major carotenoids and cryptoxanthin, 13-cis- $\beta$-carotene and 9 -cis- $\beta$-carotene were also present in low concentrations (Fig. 1). There was no lutein contained in the spirulina that we studied, and echinenone was too small to affect the experiment (Fig. 1).

Due to the different times at which the human studies were conducted in the USA (2008) and China (2006), the ${ }^{2} \mathrm{H}$-labelled spirulina was harvested in different batches. The concentration of spirulina zeaxanthin was $0.66 \mathrm{mg} / \mathrm{g}$ in the batch for American volunteers and $0.74 \mathrm{mg} / \mathrm{g}$ for Chinese volunteers; therefore, the dose of labelled spirulina zeaxanthin was $2.63 \mathrm{mg}(4.61 \mu \mathrm{mol})$ for American volunteers and $3.68 \mathrm{mg}$ $(6.46 \mu \mathrm{mol})$ for Chinese volunteers (Table 1 )

Using LC-APCI-MS, the most abundant protonated molecules of unlabelled zeaxanthin were identified at $\mathrm{m} / z 569$ (zeaxanthin $+\mathrm{H}^{+}$), and ions of anhydrozeaxanthin at $\mathrm{m} / \mathrm{z}$ 551 (zeaxanthin $+\mathrm{H}^{+}-\mathrm{H}_{2} \mathrm{O}$ ) with an abundance of $12 \cdot 6 \%$ (Fig. 2(a)). About $99 \%$ of zeaxanthin in the labelled spirulina was enriched with ${ }^{2} \mathrm{H}$, and Gaussian distribution of isotopomers of zeaxanthin had the most abundant

Table 1. Baseline concentrations of serum lutein and zeaxanthin, and serum response to labelled spirulina zeaxanthin in American and Chinese subjects (Ranges, mean values and standard deviations)

\begin{tabular}{|c|c|c|c|c|c|c|}
\hline \multirow[t]{2}{*}{ Subjects... } & \multicolumn{3}{|c|}{ American } & \multicolumn{3}{|c|}{ Chinese } \\
\hline & Range & Mean & SD & Range & Mean & SD \\
\hline Batch of spirulina (year) & \multicolumn{3}{|c|}{2008} & \multicolumn{3}{|c|}{2006} \\
\hline Dosage of zeaxanthin $(\mathrm{mg})$ & \multicolumn{3}{|c|}{$2 \cdot 63$} & \multicolumn{3}{|c|}{$3 \cdot 68$} \\
\hline Baseline concentration of serum lutein $(\mu \mathrm{mol} / /)^{\star}$ & $0.12-0.18$ & 0.16 & 0.03 & $0.27-0.52$ & 0.39 & 0.09 \\
\hline Baseline concentration of serum zeaxanthin $(\mu \mathrm{mol} / /)^{\star}$ & $0.04-0.07$ & 0.06 & 0.01 & $0.05-0.09$ & 0.07 & 0.01 \\
\hline Concentration of serum zeaxanthin $1 \mathrm{~d}$ post-supplementation $(\mu \mathrm{mol} / \mathrm{l})$ & $0.09-0.14$ & 0.11 & 0.02 & $0.11-0.24$ & 0.15 & 0.04 \\
\hline Highest value of labelled zeaxanthin as percentage of total zeaxanthin (\%) & $59-65$ & 62 & NS & $43-56$ & 49 & NS \\
\hline AUC of labelled zeaxanthin $(\mathrm{nmol} \times \mathrm{d}) \dagger$ & $1167-1542$ & 1346 & 153 & $998-1851$ & 1279 & 293 \\
\hline Average serum response $(\mathrm{nmol} \times \mathrm{d} / \mu \mathrm{mol}) \ddagger$ & $254-335$ & 293 & 33 & $154-285$ & 197 & 45 \\
\hline
\end{tabular}

AUC, area under the curve.

*Baseline concentration was measured $4 \mathrm{~d}$ before the supplementation of spirulina.

† AUC was measured over $15 \mathrm{~d}$ for all subjects.

$\ddagger$ Average serum response is the $15 \mathrm{~d}$ area under the labelled zeaxanthin response curve per $\mu \mathrm{mol}$ of consumed spirulina zeaxanthin. 

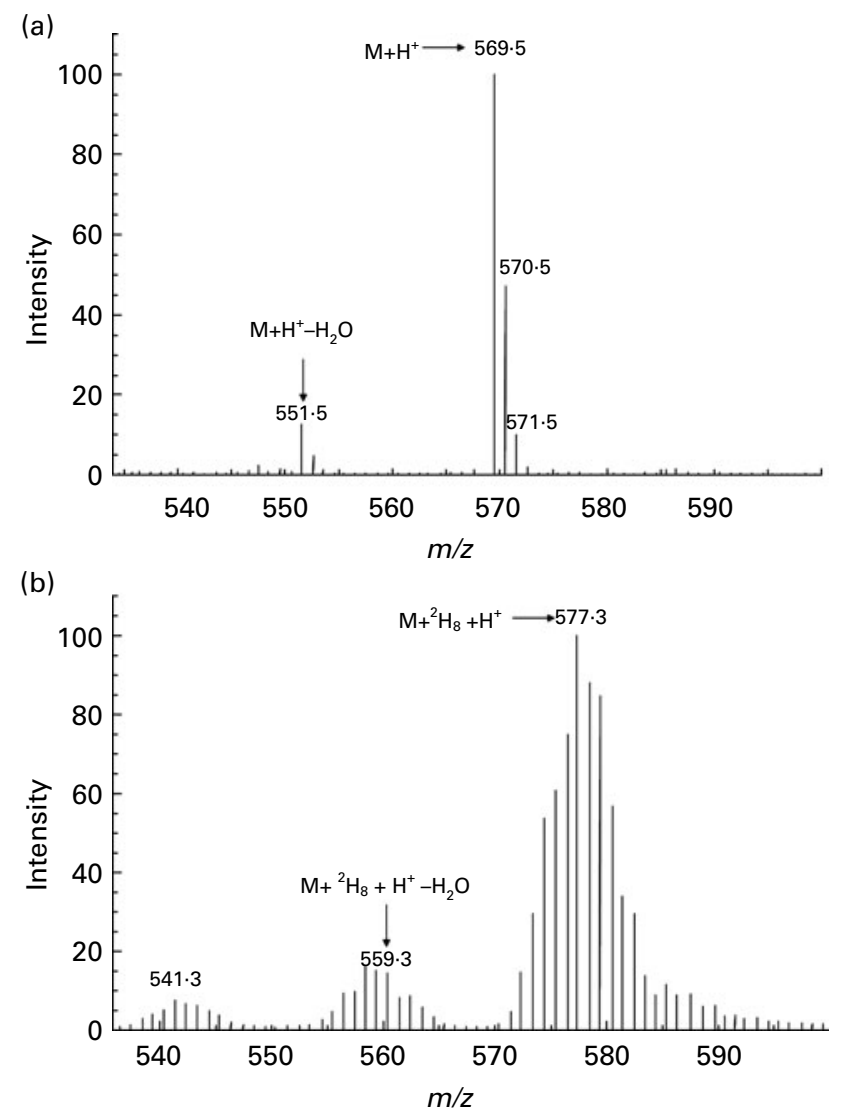

Fig. 2. Mass spectra of unlabelled and labelled zeaxanthin analysed by LC-atmospheric pressure chemical ionisation-MS. (a) Molecular mass of unlabelled zeaxanthin standard; (b) isotopomer distribution of zeaxanthin fraction from ${ }^{2} \mathrm{H}$-labelled spirulina.

enrichment of $8{ }^{2} \mathrm{H}$ at $\mathrm{m} / z 577$ (zeaxanthin $+{ }^{2} \mathrm{H}_{8}+\mathrm{H}^{+}$; Fig. 2(b)). Similar isotopomer distribution of anhydrozeaxanthin ions (zeaxanthin $+{ }^{2} \mathrm{H}_{8}+\mathrm{H}^{+}-\mathrm{H}_{2} \mathrm{O}$, zeaxanthin $+{ }^{2} \mathrm{H}_{8}+\mathrm{H}^{+}$ $\left.-2 \mathrm{H}_{2} \mathrm{O}\right)$ at $m / z 559$ and $m / z 541$ were also observed, with the abundance of $15 \cdot 1$ and $7 \cdot 5 \%$, respectively (Fig. 2(b)).

\section{Enrichment of labelled spirulina zeaxanthin in circulation in human subjects}

The representative HPLC chromatographs and mass spectra of human serum zeaxanthin (from American subject 2) before and $48 \mathrm{~h}$ after supplementation with spirulina are shown in Fig. 3. The HPLC chromatographs demonstrate that serum extracts before and after supplementation shared similar carotenoid profiles (Fig. 3). All trans-lutein eluted at $6.9 \mathrm{~min}$, and all trans-zeaxanthin eluted at $8.5 \mathrm{~min}$. The amount of lutein decreased slightly $48 \mathrm{~h}$ post-supplementation (Fig. 3(a), before supplementation), but the amount of zeaxanthin greatly increased $48 \mathrm{~h}$ post-supplementation (Fig. 3(a), after supplementation).

According to the distribution of zeaxanthin mass (Fig. 2), the peaks of $m / z 569-571$ were assigned as endogenous unlabelled zeaxanthin, while those of $\mathrm{m} / z$ 573-583 were assigned as the ${ }^{2} \mathrm{H}$-labelled zeaxanthin from spirulina. Extracted ion chromatographs of unlabelled and labelled zeaxanthin showed that, before the supplementation, no labelled zeaxanthin was detectable at $8.5 \mathrm{~min}$ (Fig. 3(b), before supplementation); however, $48 \mathrm{~h}$ after supplementation, both labelled and unlabelled zeaxanthin were present (Fig. 3(b), after supplementation). The Gaussian isotopomer distribution of ${ }^{2} \mathrm{H}$-labelled zeaxanthin was clearly visible after supplementation (Fig. 3(c), after supplementation), but not before supplementation (Fig. 3(c), before supplementation), in the mass spectrum of the zeaxanthin peak maximum.

\section{Serum responses to labelled spirulina zeaxanthin in American and Chinese volunteers}

Although we followed the labelled zeaxanthin trace in the circulation up to $45 \mathrm{~d}$, only data over $21 \mathrm{~d}$ are presented in the graphs. The concentrations of serum zeaxanthin increased dramatically about $1-2 \mathrm{~d}$ post-supplementation in all subjects (data not shown). The mean value of serum zeaxanthin concentration $1 \mathrm{~d}$ after supplementation increased from baseline of 0.06 to $0.11 \mu \mathrm{mol} / 1$ in American subjects and from baseline of 0.07 to $0.15 \mu \mathrm{mol} / 1$ in Chinese subjects (Table 1). Over the $21 \mathrm{~d}$ of this study, the serum concentrations of total zeaxanthin fluctuated in some subjects (e.g. American subject 1 and Chinese subject 7), but were relatively stable in others (e.g. American subject 2 and Chinese subject 10; Fig. 4). In all subjects, the enrichment of labelled zeaxanthin in the circulation reached a maximum between 1 and $3 \mathrm{~d}$ postsupplementation, and then decreased with little variation (Fig. 5 and data not shown). The amount of serum labelled zeaxanthin followed a similar pattern (Fig. 5). The mean highest value of labelled zeaxanthin as percentage of total zeaxanthin in American subjects was 62\% (range 59-65\%), and was $49 \%$ in Chinese subjects (range 43-56\%; Table 1).

\section{Area under the curve of labelled spirulina zeaxanthin responses in American and Chinese subjects}

The AUC of labelled zeaxanthin was integrated using amounts of labelled zeaxanthin $v$. time over $15 \mathrm{~d}$ due to the detectability of the zeaxanthin. American subjects had a mean value of $1346 \mathrm{nmol} \times \mathrm{d}$ and Chinese subjects had a mean value of $1279 \mathrm{nmol} \times \mathrm{d}$ (Table 1$)$. The mean value of the average serum response, which is the $15 \mathrm{~d}$ area under the serum labelled zeaxanthin response curve (in nmol $\times \mathrm{d}$ ) divided by the consumed zeaxanthin dose (in $\mu \mathrm{mol}$ ), was $293 \mathrm{nmol}$ $\times \mathrm{d} / \mu \mathrm{mol}$ in American subjects (range 254-335), and was $197 \mathrm{nmol} \times \mathrm{d} / \mu \mathrm{mol}$ in Chinese subjects (range 154-285).

\section{Discussion}

In the present study, we utilised ${ }^{2} \mathrm{H}$ labelling and LC-APCI-MS to determine the bioavailability of spirulina zeaxanthin in human subjects. The peaks of enrichment of $\left(\mathrm{M}+{ }^{2} \mathrm{H}_{8}\right)$ and measurable isotopomers from $\left(\mathrm{M}+{ }^{2} \mathrm{H}_{1}\right)$ through $\left(\mathrm{M}+{ }^{2} \mathrm{H}_{14}\right)$ of labelled zeaxanthin were easily discernible from unlabelled zeaxanthin in human serum extracts (Fig. 3). After the study, subjects took a single dose of spirulina, and the labelled zeaxanthin was detected as early as $1 \mathrm{~d}$ post-supplementation 
(a) 30 [ Before supplementation
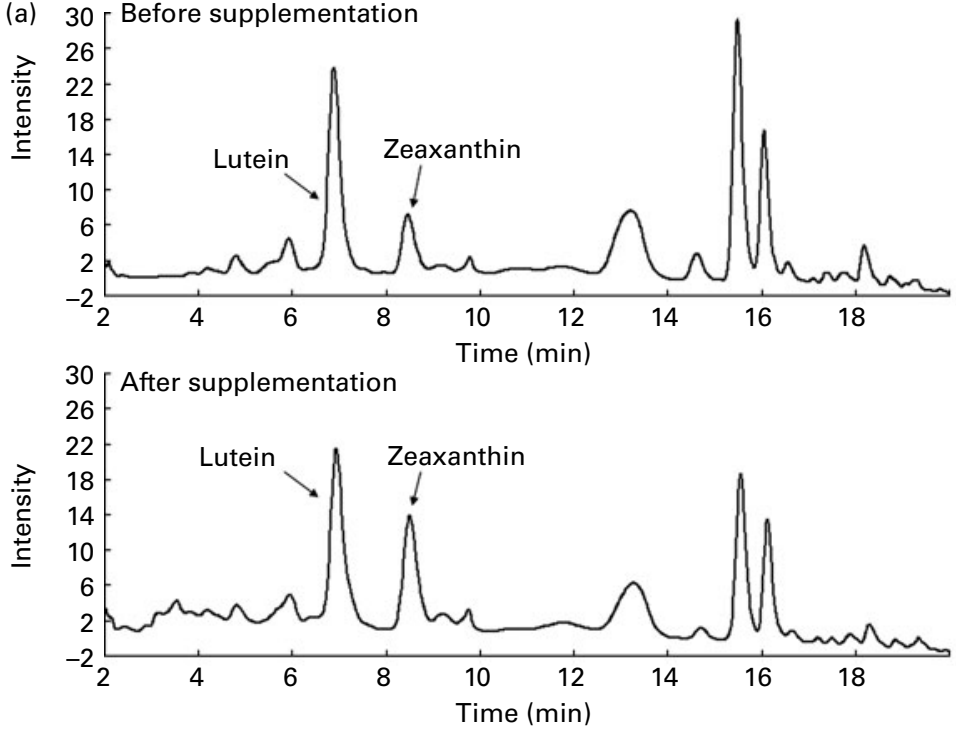

(b) 25 Before supplementation
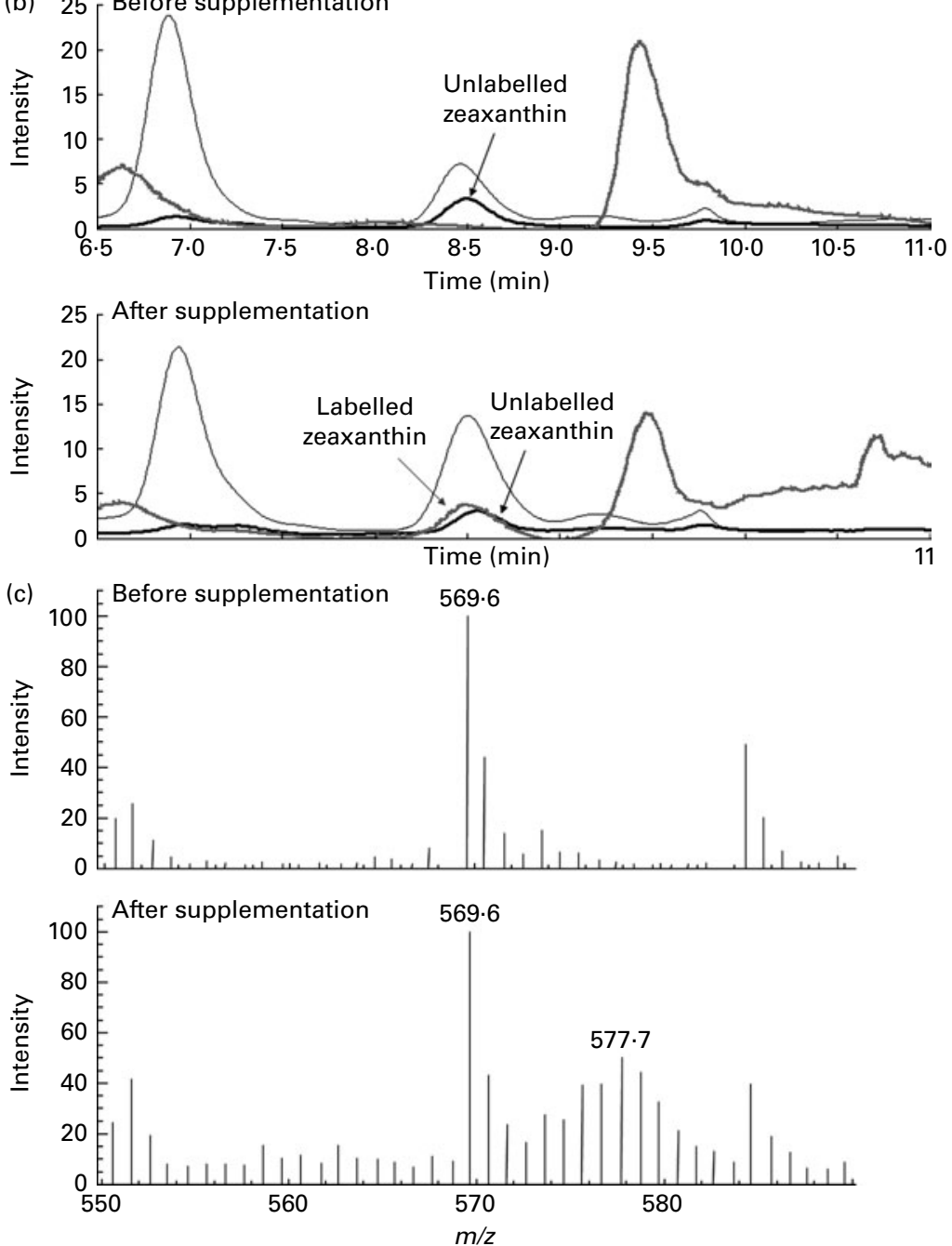

Fig. 3. LC-atmospheric pressure chemical ionisation-MS analysis of serum extracts (American subject 2) before and after supplementation with ${ }^{2} \mathrm{H}$-labelled spiruina. (a) HPLC separation of the carotenoids in the serum. (b) Extracted ion chromatograms (EIC) of unlabelled $(\mathrm{m} / \mathrm{z} 569-571,-)$ and labelled $(\mathrm{m} / \mathrm{z} 573-583$, 一) zeaxanthin. —, UV450. (c) Mass spectra at the peak maximum of zeaxanthin before and $48 \mathrm{~h}$ after supplementation with ${ }^{2} \mathrm{H}$-labelled spirulina. 


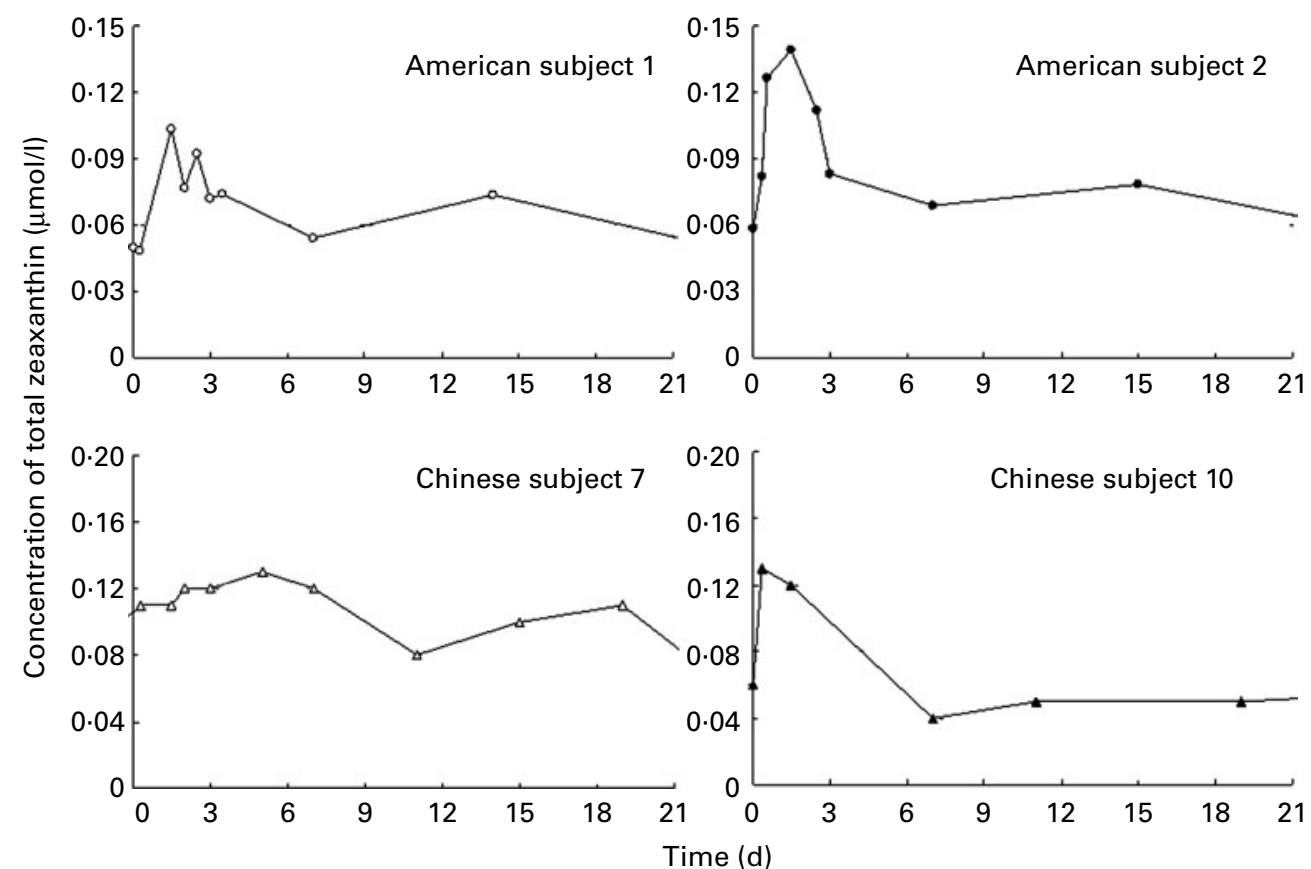

Fig. 4. Serum concentrations of total zeaxanthin (in $\mu \mathrm{mol} / \mathrm{l}$ ) after supplementation with spirulina over $21 \mathrm{~d}$ in representative subjects (American subjects 1 , 2 and Chinese subjects 7,10$)$.

(Fig. 5), and enrichments could be measured in circulation up to $45 \mathrm{~d}$ post-feeding (data not shown). Therefore, the serum response to labelled zeaxanthin from spirulina was sensitively detected with minimal influences by their daily dietary intake of zeaxanthin.

Our present study showed that spirulina is a good dietary source of zeaxanthin which can effectively increase serum zeaxanthin concentration in humans. There are several studies reporting the influence of dietary zeaxanthin on subject
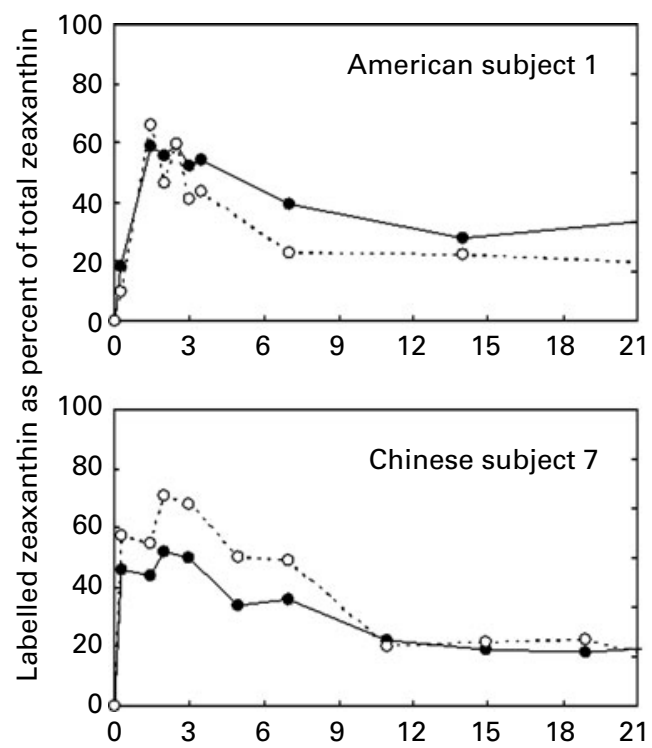

plasma zeaxanthin concentrations ${ }^{(22-26)}$. In one study with older adults, egg-yolk supplementation of a beef tallow diet or a maize oil diet increased plasma zeaxanthin concentrations by 142 or $114 \%$, respectively ${ }^{(26)}$. A similar study of a 12-week egg intervention also showed that egg intake significantly increased serum zeaxanthin concentrations in women ${ }^{(22)}$. In a recently reported study, consumption of four egg-yolks/d for 5 weeks in older adults increased serum zeaxanthin concentrations from 0.03 to $0.06 \mu \mathrm{mol} / \mathrm{l}^{(23)}$.
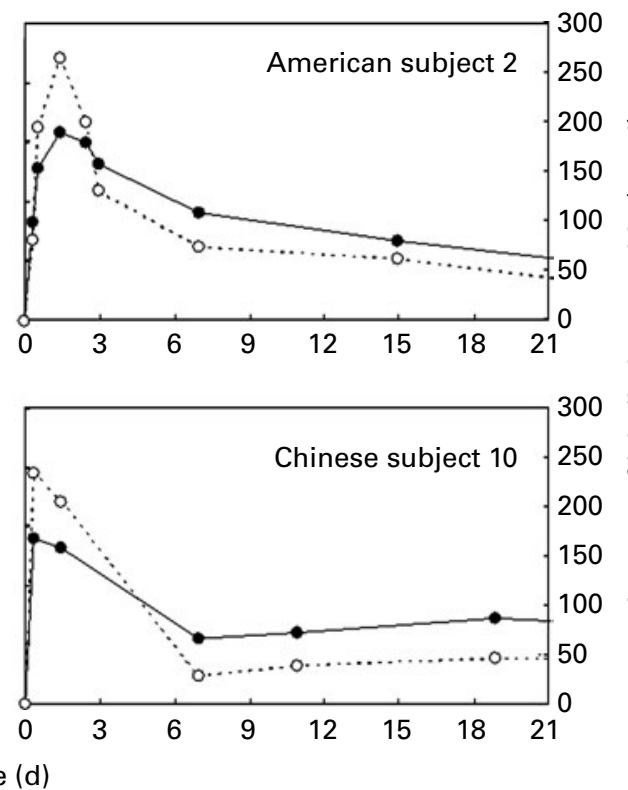

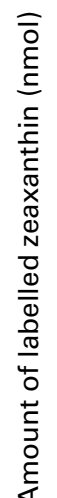

Fig. 5. Serum responses to labelled zeaxanthin after supplementation with spirulina in representative subjects (American subjects 1, 2 and Chinese subjects 7 , 10). ${ }^{2} \mathrm{H}$-labelled spirulina zeaxanthin as percentage of total zeaxanthin ( - and $\bullet$, left axis) and amount of labelled zeaxanthin (in $\mathrm{nmol}, \ldots . .$. and $\mathrm{O}$, right axis) in the circulation over $21 \mathrm{~d}$ are presented. 
In our study, a single dose of 4.0 or $5.0 \mathrm{~g}$ spirulina significantly increased the zeaxanthin concentrations in the circulation of both American and Chinese subjects. One day after supplementation, the mean concentration of total serum zeaxanthin increased from 0.06 to $0.11 \mu \mathrm{mol} / 1$ in American subjects ( $2.63 \mathrm{mg}$ zeaxanthin dose) and from 0.07 to $0.15 \mu \mathrm{mol} / 1$ in Chinese subjects ( $3.68 \mathrm{mg}$ zeaxanthin dose; Table 1). Because egg-yolks contain a substantial amount of cholesterol, spirulina could be a good, alternative source of zeaxanthin for those individuals seeking to limit their dietary cholesterol intake. Consumption of vegetables such as spinach and maize at dietary levels have been reported to result in no increases in plasma zeaxanthin concentrations ${ }^{(25)}$.

There are several factors that might be contributing to the high bioavailability of spirulina zeaxanthin in humans. First, dried spirulina powder contains an extremely high concentration of zeaxanthin, about 50-300 times higher than that in cooked egg-yolk, maize or pepper ${ }^{(13)}$. In the present study, a single dose of 2.6 or $3.7 \mathrm{mg}$ zeaxanthin was administrated to subjects, which might be difficult to achieve if other diets are chosen. Second, the spirulina cell wall is composed of proteins and peptidoglycans that can be digested easily, which helps zeaxanthin to be released from the food matrix $^{(14,16)}$. In addition, spirulina contains high concentrations of NEFA that can reach $9-14 \%$ of the dry weight of spirulina ${ }^{(16,27-29)}$. Since fat can increase the bioavailability of carotenoid absorption ${ }^{(22,23)}$, the lipid matrix contained in spirulina may facilitate the absorption of zeaxanthin.

We observed a significant difference of average serum response to a single dose of spirulina zeaxanthin in middleaged American and Chinese males (Table 1). However, it should be noted that the difference we observed was from two small groups (four American subjects, ten Chinese subjects), and no conclusion on racial differences of zeaxanthin absorption could be made at this point. Since it is known that both age and sex may affect the serum response to carotenoids $^{(30-32)}$, the substantial response to spirulina zeaxanthin should be further investigated in other populations. With the present study, our data strongly suggested that spirulina is a rich dietary zeaxanthin source, which might benefit the general population for visual health.

\section{Acknowledgements}

The authors thank David A. Dworak and Chee-Ming Li for their assistance with producing the ${ }^{2} \mathrm{H}$-labelled spirulina. This work was supported by the Nestlé Foundation, Lausanne, Switzerland and by the US Department of Agriculture, under Cooperative Agreements 58-1950-7-707, 58-1950-9-001 and 58-6250-6-001. The authors' contributions were as follows: B. Y. conducted the sample and data analyses, and wrote the manuscript; R. M. R. and G. T. designed the study, conducted the US study and revised the manuscript; J. W., Y. W. and Z. W. conducted the human study and collected samples in China; P. M. S. was affiliated with the University Hospital and Nestlé Foundation (Lausanne, Switzerland) and revised the manuscript; S. Y. supervised the human study in China; M. A. G. produced the labelled spirulina, provided the spirulina diets and revised the manuscript. None of the authors had any personal or financial conflicts of interest.

\section{References}

1. Whitehead AJ, Mares JA \& Danis RP (2006) Macular pigment: a review of current knowledge. Arch Ophthalmol 124, 1038-1045.

2. Landrum JT \& Bone RA (2001) Lutein, zeaxanthin, and the macular pigment. Arch Biochem Biophys 385, 28-40.

3. Ahmed SS, Lott MN \& Marcus DM (2005) The macular xanthophylls. Surv Ophthalmol 50, 183-193.

4. Junghans A, Sies H \& Stahl W (2001) Macular pigments lutein and zeaxanthin as blue light filters studied in liposomes. Arch Biochem Biophys 391, 160-164.

5. Malinow MR, Feeney-Burns L, Peterson LH, et al. (1980) Dietrelated macular anomalies in monkeys. Invest Ophthalmol Vis Sci 19, 857-863.

6. Leung IY, Sandstrom MM, Zucker CL, et al. (2004) Nutritional manipulation of primate retinas, II: effects of age, $n$ - 3 fatty acids, lutein, and zeaxanthin on retinal pigment epithelium. Invest Ophthalmol Vis Sci 45, 3244-3256.

7. Thomson LR, Toyoda Y, Langner A, et al. (2002) Elevated retinal zeaxanthin and prevention of light-induced photoreceptor cell death in quail. Invest Ophthalmol Vis Sci $\mathbf{4 3}$, 3538-3549.

8. Thomson LR, Toyoda Y, Delori FC, et al. (2002) Long term dietary supplementation with zeaxanthin reduces photoreceptor death in light-damaged Japanese quail. Exp Eye Res 75, 529-542.

9. Johnson EJ (2010) Age-related macular degeneration and antioxidant vitamins: recent findings. Curr Opin Clin Nutr Metab Care 13, 28-33.

10. Tan JS, Wang JJ, Flood V, et al. (2008) Dietary antioxidants and the long-term incidence of age-related macular degeneration: the Blue Mountains Eye Study. Ophthalmology 115, 334-341.

11. Seddon JM, Ajani UA, Sperduto RD, et al. (1994) Dietary carotenoids, vitamins A, C, and E, and advanced age-related macular degeneration. Eye Disease Case-Control Study Group. JAMA 272, 1413-1420.

12. Mares-Perlman JA, Fisher AI, Klein R, et al. (2001) Lutein and zeaxanthin in the diet and serum and their relation to age-related maculopathy in the third national health and nutrition examination survey. Am J Epidemiol 153, 424-432.

13. Perry A, Rasmussen H \& Johnson EJ (2009) Xanthophyll (lutein, zeaxanthin) content in fruits, vegetables and corn and egg products. J Food Compos Anal 22, 9-5.

14. Maiani G, Caston MJ, Catasta G, et al. (2009) Carotenoids: actual knowledge on food sources, intakes, stability and bioavailability and their protective role in humans. Mol Nutr Food Res 53, Suppl. 2, S194-S218.

15. Miranda MS, Cintra RG, Barros SB, et al. (1998) Antioxidant activity of the microalga Spirulina maxima. Braz J Med Biol Res 31, 1075-1079.

16. Ciferri O (1983) Spirulina, the edible microorganism. Microbiol Rev 47, 551-578.

17. Gireesh T, Nair PP \& Sudhakaran PR (2004) Studies on the bioavailability of the provitamin A carotenoid, beta-carotene, using human exfoliated colonic epithelial cells. Br J Nutr $\mathbf{9 2}$, $241-245$.

18. Annapurna VV, Deosthale YG \& Bamji MS (1991) Spirulina as a source of vitamin A. Plant Foods Hum Nutr 41, 125-134.

19. Wang J, Wang Y, Wang Z, et al. (2008) Vitamin A equivalence of spirulina beta-carotene in Chinese adults as assessed by 
using a stable-isotope reference method. Am J Clin Nutr $\mathbf{8 7}$, $1730-1737$.

20. Traber MG (2000) The bioavailability bugaboo. Am J Clin Nutr 71, 1029-1030.

21. Ford ES \& Giles WH (2000) Serum vitamins, carotenoids, and angina pectoris: findings from the National Health and Nutrition Examination Survey III. Ann Epidemiol 10, 106-116.

22. Wenzel AJ, Gerweck C, Barbato D, et al. (2006) A 12-wk egg intervention increases serum zeaxanthin and macular pigment optical density in women. J Nutr 136, 2568-2573.

23. Vishwanathan R, Goodrow-Kotyla EF, Wooten BR, et al. (2009) Consumption of 2 and 4 egg yolks/d for 5 wk increases macular pigment concentrations in older adults with low macular pigment taking cholesterol-lowering statins. Am J Clin Nutr 90, 1272-1279.

24. Goodrow EF, Wilson TA, Houde SC, et al. (2006) Consumption of one egg per day increases serum lutein and zeaxanthin concentrations in older adults without altering serum lipid and lipoprotein cholesterol concentrations. J Nutr 136, 2519-2524
25. Hammond BR Jr, Johnson EJ, Russell RM, et al. (1997) Dietary modification of human macular pigment density. Invest Ophthalmol Vis Sci 38, 1795-1801.

26. Handelman GJ, Nightingale ZD, Lichtenstein AH, et al. (1999) Lutein and zeaxanthin concentrations in plasma after dietary supplementation with egg yolk. Am J Clin Nutr 70, 247-251.

27. Yeum KJ \& Russell RM (2002) Carotenoid bioavailability and bioconversion. Annu Rev Nutr 22, 483-504.

28. Zaripheh S \& Erdman JW (2002) Factors that influence the bioavailablity of xanthophylls. J Nutr 132, 531S-534S.

29. Hudson BJ \& Karis IG (1974) The lipids of the alga Spirulina. J Sci Food Agric 25, 759-763.

30. Schweigert FJ, Klingner J, Hurtienne A, et al. (2003) Vitamin A, carotenoid and vitamin E plasma concentrations in children from Laos in relation to sex and growth failure. Nutr J 2, 17.

31. Nierenberg DW, Stukel TA, Baron JA, et al. (1991) Determinants of increase in plasma concentration of beta-carotene after chronic oral supplementation. The Skin Cancer Prevention Study Group. Am J Clin Nutr 53, 1443-1449.

32. Castenmiller JJ \& West CE (1998) Bioavailability and bioconversion of carotenoids. Annu Rev Nutr 18, 19-38. 